\title{
Evaluasi User interface Web Commerce Menggunakan Aturan Eight golden rules
}

Lelycia Darlianti Putri , Gita Indah Marthasari, Wahyu Andhyka Kusuma

Program Studi Informatika, Universitas Muhammadiyah Malang

Email: lelyciadarliantiputri@umm.ac.id

\section{Info Artikel}

\section{Kata Kunci :}

marketplace, user interface, eight golden rules, website.

\section{Keywords :}

marketplace , user interface, eight

golden rules, website

\section{Tanggal Artikel}

Dikirim : 4 April 2021

Diterima : 30 Mei 2021

\begin{abstract}
Abstrak
Semakin banyaknya marketplace membuat pengguna mudah melakukan penjualan dan pembelian barang/jasa. Pengguna tentunya memilih marketplace yang mudah digunakan, dari keamanan dan kenyamanan. Dalam hal ini salah satu yang mempengaruhi kenyamanan menggunakan marketplace yaitu user interface. User interface merupakan salah satu penyebab yang dapat membuat kenaikan trafik sebuah website. Penelitian ini bertujuan untuk mencari tahu tingkat kenyamanan website marketplace. Metode yang dipakai adalah penelitian kualitatif dengan aturan eight golden rules karena aturan tersebut lebih mudah diterima dan dirasa nyaman oleh user. Aturan eight golden rules digunakan pada saat proses wawancara sebagai indikator protokol wawancara. Proses analisa data menggunakan metode penelitian kualitatif yaitu reduksi data, kategorisasi, sintesisasi, dan menyusun hipotesis kerja. Pada validasi data terdiri dari kredibilitas data, Keteralihan, kebergantungan dan kepastian. Hasil dari penelitian ini adalah website Tokopedia melebihi website Shopee dan Bukalapak, karena website Tokopedia cenderung mempunyai konsistensi warna, tata letak, fonthuruf yang lebih baik, kegunaan yang universal dapat membantu pengguna, interface dapat mencegah kesalahan serius, perintah undo/back tidak membingungkan pengguna, tampilan yang sederhana dan mudah diingat. Dari penelitian ini, dapat diketahui bahwa user interface website Tokopedia dapat dikatakan mudah dan nyaman digunakan oleh pengguna karena memenuhi aturan eight golden rules
\end{abstract}

\begin{abstract}
Abstarct
More marketplace s make it easy for users to make sales and purchases of goods/services. Users certainly choose a marketplace that is easy to use, from security and comfort. In this case one that affects the convenience of using the marketplace is user interface. User interface is one of causes that can increase website traffic. This research aims to find out level of comfort of marketplace website. The method used is qualitative research with eight golden rules because the rules are more easily accepted and felt comfortable by user. Eight golden rules are used during interview process as an indicator of the interview protocol. Process of analyzing data uses qualitative research methods, namely data reduction, categorization, synthesis, and working hypothesis. Data validation consists of data credibility, dependability, certainty. The results of this study are Tokopedia website exceeds Shopee and Bukalapak, because Tokopedia website tends to have better color consistency, layout, fonts, universal usability can help the user, interface can prevent serious errors, command undo/back doesn't confuse user, simple and easy to remember display. From this research, it can be seen that user interface Tokopedia website can be said to be easy and convenient to use because it meets the eight golden rules .
\end{abstract}




\section{PENDAHULUAN}

Pada era ini, penjualan dan pembelian barang atau jasa dapat dilakukan melalui jaringan komputer termasuk internet. Hal itu ditunjang dengan munculnya perusahaan-perusahaan yang mulai menawarkan produknya melalui website. Banyaknya marketplace yang ada membuat para pengguna mudah dalam melakukan penjualan dan pembelian barang atau jasa [1]. Pengguna tentunya memilih marketplace yang mudah digunakan, dari segi keamanan dan kenyamanan. Dalam hal ini salah satu yang mempengaruhi kenyamanan dari menggunakan marketplace itu sendiri yaitu antarmuka pengguna (user interface).

User interface merupakan kumpulan tampilan grafis yang dipahami oleh pengguna komputer yang diprogram sedemikian rupa sehingga dapat dibaca oleh sistem operasi komputer dan berfungsi seperti seharusnya [2]. User interface juga merupakan salah satu penyebab yang dapat membuat kenaikan traffic pada sebuah website, karena pengguna dapat berinteraksi dengan logika pemrograman melalui user interface. Software yang baik selalu memiliki user interface yang bukan hanya bagus, tetapi mudah dipahami oleh user [3].

Penelitian ini bertujuan untuk mencari tahu tingkat kenyamanan dari website Tokopedia dari sisi pembelian barang. Dari data pada website Iprice Insight dimana website ini merupakan website yang berfungsi untuk mengukur peringkat dari website marketplace diketahui bahwa dari daftar 50 website \& aplikasi E-Commerce dalam data kuartal 1 tahun 2019 website marketplace Tokopedia berada pada urutan pertama dalam banyaknya pengunjung web bulanan sebanyak 137 juta kunjungan [4]. Website Tokopedia ini juga akan dibandingkan dengan website yang berada pada urutan kedua dan ketiga dari peringkat tersebut yaitu website Shopee dan website Bukalapak.

Tokopedia merupakan sebuah website jual beli online / toko online (e-commerce) di Indonesia yang mengusung model bisnis marketplace. Sasaran pasar pada website Tokopedia adalah para penjual dan pembeli, website Tokopedia menyediakan tempat bagi para penjual untuk memasarkan barang-barangnya, dan para pembeli yang bisa melihat dan memilih barang yang akan dibelinya.

Penelitian ini didukung oleh beberapa penelitian yang sudah dilakukan sebelumnya oleh beberapa peneliti diantaranya User interface Evaluation of Indonesian Online News Portals: Case Study of Vivanews and Detikcom. Penelitian ini bertujuan untuk evaluasi website Vivanews dan Detikcom menggunakan teori eight golden rules. Hasil dari penelitian tersebut berupa pernyataan perbandingan dari kedua website yang sudah di evaluasi yang sesuai dengan teori eight golden rules [5].

Kemudian penelitian yang kedua dengan judul Evaluasi Interface Aplikasi Ujian Nasional Berbasis Komputer yang bertujuan untuk mengetahui berapa tingkat keberterimaan user interface aplikasi ujian nasional berbasis komputer [6]. Metode yang digunakan dalam penelitian ini yaitu dengan melakukan penyebaran kuesioner yang menggunakan acuan eight golden rules. Kemudian untuk menghitung hasil dari kuesioner menggunakan skala likert. Validasi hasil dengan menggunakan uji validitas dan uji reliabilitas.

Penelitian yang ketiga yaitu Evaluasi User interface Pada Aplikasi Pacitan Tourism dimana penelitian ini bertujuan untuk mengevaluasi sekaligus mengembangkan aplikasi Pacitan Tourism. Metode yang digunakan yaitu dengan menggunakan eight golden rules sebagai indikator sebagai dasar pembuatan kuesioner, kemudian menggunakan pengukuran data dari kuesioner dengan skala likert dan juga dilakukan uji validitas dan reliabilitas [7].

Penelitian yang keempat dengan judul Evaluasi Usability Aplikasi Pelayanan Masyarakat Jangka Joyoboyo Polres Kediri dimana penelitian ini bertujuan untuk mengevaluasi aplikasi pelayanan masyarakat dengan menggunakan metode aturan eight golden rules dan dikombinasikan dengan salah satu metode usability testing yaitu retrospective think-aloud guna memperkuat hasil dari evaluasi. Penelitian ini menggunakan teknik quota sampling untuk mendapatkan sampel penelitian. Kemudian responden diminta untuk mengisi kuesioner untuk mendapatkan hasil dari tingkat usability system [8].

Penelitian yang akan dilakukan oleh peneliti yaitu melakukan penelitian kualitatif untuk mendapatkan hasil analisa dari evaluasi user interface dengan menggunakan aturan eight golden rules. Objek yang akan diteliti merupakan website Tokopedia dari segi pembelian barang dimana penelitian ini merujuk pada evaluasi kualitas dari website Tokopedia. Perbedaan dari penelitian sebelumnya yaitu penelitian ini menggunakan narasumber yang paham mengenai user interface dan juga penelitian ini menggunakan metode kualitatif sebagai analisa dan validasi data.

Alasan Menggunakan aturan eight golden rules sendiri karena eight golden rules merupakan salah satu aturan dasar yang digunakan dalam merancang antarmuka suatu sistem yang dibuat oleh Ben Shneiderman. Rules yang ditawarkan pada eight golden rules diketahui lebih mudah diterima dan dirasa nyaman oleh user.

Eight golden rules memiliki 8 variabel yaitu strive for consistency (mengupayakan konsistensi), universal usability, offer informative feedback (menawarkan feedback informatif), design dialogue to yield closure (desain dialog untuk menghasilkan penutupan), offer simple error handling (menawarkan penanganan kesalahan sederhana), permit easy reversal of actions (mengizinkan tindakan balik yang mudah), support internal locus of control (mendukung tempat kendali internal), dan reduce short-term memory of load (mengurangi beban memori jangka pendek). Evaluasi user interface dengan eight golden rules ini 
akan dilakukan oleh 3 orang ahli dalam bidang desain user interface. Pertanyaan yang akan diajukan kepada evaluator mengacu pada variabel eight golden rules. Hasil penilaian evaluasi ini nantinya akan diketahui kualitas dari website Tokopedia

\section{METODE PENELITIAN}

Dalam penelitian ini menggunkan metode Eight golden rules. Eight golden rules merupakan salah satu aturan dasar yang digunakan dalam merancang antarmuka suatu sistem yang dibuat oleh Ben Shneiderman. Rules yang ditawarkan pada eight golden rules lebih mudah diterima dan dirasa nyaman oleh user.

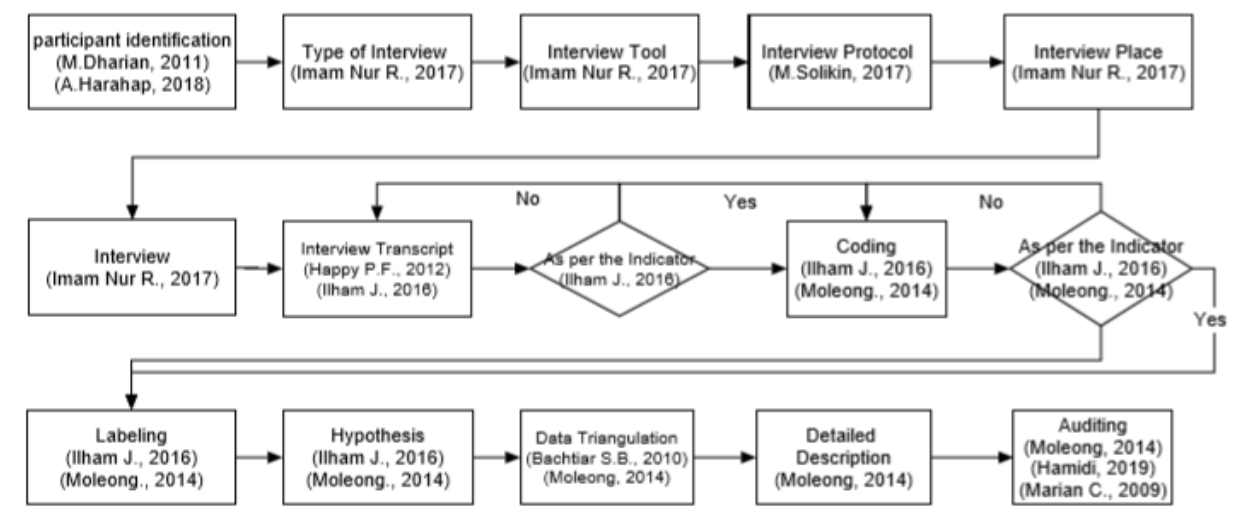

Gambar 1. Alur Penelitian

Pada gambar 1 merupakan alur dari penelitian di mana dilakukan identifikasi aspek penelitian, kemudian menentukan jenis wawancara, alat wawancara, protokol wawancara, tempat wawancara yang akan dipakai dalam penelitian. Penelitian ini menggunakan model penelitian kualitatif dimana terdapat proses tersendiri untuk penelitiannya. Proses penelitian kualitatif meliputi pengambilan data dengan metode wawancara, analisa data dengan metode reduksi data (pengkodean), kategorisasi, sintesisasi (pelabelan), dan menyusun hipotesis kerja, kemudian diakhiri dengan validitas data dengan metode kredibilitas (triangulasi data), keteralihan (uraian rinci), kebergantungan dan kepastian (auditing) [9].

\subsection{Wawancara}

Jenis wawancara yang digunakan pada penelitian ini yaitu jenis wawancara terstruktur yang dikemukakan oleh [10]. Jenis wawancara terstruktur adalah wawancara yang dimana peneliti menetapkan sendiri masalah dan pertanyaan yang akan diajukan kepada terwawancara. Format wawancara yang digunakan dinamakan protokol wawancara. Protokol wawancara disusun berdasarkan pada masalah dalam rancangan penelitian. Dalam penelitian ini, pertanyaan untuk narasumber/terwawancara menggunakan acuan dalam variabel dan indikator dari eight golden rules .

Dalam menentukan tempat wawancara sebisa mungkin didiskusikan bersama dengan narasumber. Pada penelitian ini tempat wawancara dilakukan pada tempat narasumber bekerja dimana tempat ini dirasa nyaman oleh narasumber karena waktu pelaksanaan yang termasuk pada hari kerja. Setelah proses wawancara selesai, peneliti harus membuat transkrip wawancara.

\subsection{Reduksi data (pengkodean)}

Reduksi data adalah awal dari proses analisa data. Dalam reduksi data dilakukan dua langkah proses. proses ini menggunakan open coding. Langkah yang dilakukan pada reduksi data antara lain :

a. Identifikasi satuan (unit)

Identifikasi satuan dilakukan dengan cara menjabarkan hasil dari wawancara kemudian mencari data-data yang penting sesuai dengan indikator pertanyaan. Cara ini dilakukan dengan metode menyimpulkan gagasan utama tersirat dimana metode ini digunakan untuk menemukan gagasan utama pada hasil pertanyaan wawancara. Subject, verb, dan critical information akan diberi tanda berdasarkan warna yaitu subject dengan warna merah, verb dengan warna biru, dan critical information berwarna hijau.

b. Membuat kode

Setelah ditemukan data-data penting yang sesuai dengan indikator pertanyaan, kemudian memberi kode pada setiap data penting tersebut. pemberian kode pada setiap data dilakukan dengan cara memberikan comment yang sudah tersedia pada aplikasi microsoft office word.

\subsection{Kategorisasi}


Kategorisari dilakukan setelah mereduksi data. Kategorisasi dilakukan dengan cara memberi kategori/tema pada setiap data yang sudah direduksi. Kategori/tema pada kategorisasi merupakan indikator dari pertanyaan yang telah dibuat. Jadi data yang sudah direduksi akan dikelompokkan lagi sesuai dengan kategori pada kategorisasi.

\subsection{Sintesisasi (pelabelan)}

Sintesisasi digunakan untuk mencari kaitan antara satu data dari satu responden dengan responden yang lain. Sintesisasi mengarah pada rangkuman dari hasil pernyataan responden yang sudah di kategorikan pada tahap kategorisasi. Kemudian akan diberi label lagi sesuai dengan variabel eight golden rules .

\subsection{Menyusun 'hipotesis kerja'}

Hipotesis kerja dilakukan untuk memberikan hasil sementara pada rangkuman yang ada pada sintesisasi. Dalam hipotesis kerja akan diketahui website mana yang lebih unggul.

\subsection{Kredibilitas (triangulasi)}

Derajat kepercayaan digunakan untuk menunjukkan kepercayaan dari narasumber mengenai pendapat yang telah dikemukakan pada wawancara yang telah dilakukan. Penelitian ini menggunakan teknik triangulasi metode di mana metode ini bertujuan untuk mendapatkan data yang sama dengan metode yang berbeda. metode yang berbeda tersebut berupa wawancara, observasi dan dokumentasi[11].

\subsection{Keteralihan (Uraian Rinci)}

Teknik keteralihan dilakukan dengan cara menjabarkan hasil dari wawancara, observasi dan dokumentasi dengan memberikan kata-kata yang jelas dan dapat dipahami oleh pembaca. Kemudian, diberikan kesimpulan dari hasil yang telah dijabarkan tersebut.

\subsection{Kebergantungan dan Kepastian (Auditing)}

Kebergantungan dan kepastian dilakukan dengan proses auditing. Proses ini dilakukan pada hasil yang telah ada. Proses auditing dilakukan oleh dosen pembimbing dimana dosen pembimbing merupakan orang yang tepat karena mengetahui setiap langkah penelitian. Proses auditing dilakukan dengan mengikuti langkah proses yang mencakup identifikasi masalah penelitian, meninjau literatur, merancang kerangka kerja, mendapatkan data, analisa data, validitas data, dan kesimpulan dan saran[12].

\section{HASIL DAN PEMBAHASAN}

\subsection{Reduksi Data}

Berikut ini adalah data gambar 2 yang menjelaskan mengenai reduksi data yang di dapat dari wawancara 1. Pertanyaan Wawancara

Menurut anda apakah warna pada website tokopedia, shopee dan bukalapak itu konsisten? apakah ada perbedaan antara konsistensi warna pada 3 website tersebut?

Jawaban Responden

Menurut saya website tokopedia sudah konsisten Konsistennya itu dari brandnya sendiri, dari Website tokopedia sendiri menggunakan wama hijau dan di website-nya juga menggunakan warna hijau. Kalau di tokopedia itu dulu hanya menggunakan dua warna yaitu hijau dan jingga. Jadi hijaunya itu untuk primernya, jingga itu untuk sekundernya yang digunakan untuk tombolnya. Tapi semakin kesini tokopedia itu mengikut brand ambassador mereka.

Kalau website shopee terlalu konsisten Dalam arti menunut saya website shopee itu terlalu main satu warna saja, baik itu warna primernya atau warna sekundernya itu samal tapi, di shopee itu ada dua kategori, dimana shopee biasa itu warna jingga dan shopee mall itu warna merah. Jadi menurut saya shope tidak berani main warna.

Kalau website bukalapak sama seperti website tokopedia, jadi ada dua warna di website bukalapak. Wiebsite Bukalapak memiliki wama merah magenta sebagai warna primer dan warna sekundernya warna hijaul jadi ada dua warna dan itu konsisten sampai proses pembayaran

Gambar 2. Reduksi Data Narasumber 1 Pertanyaan 1

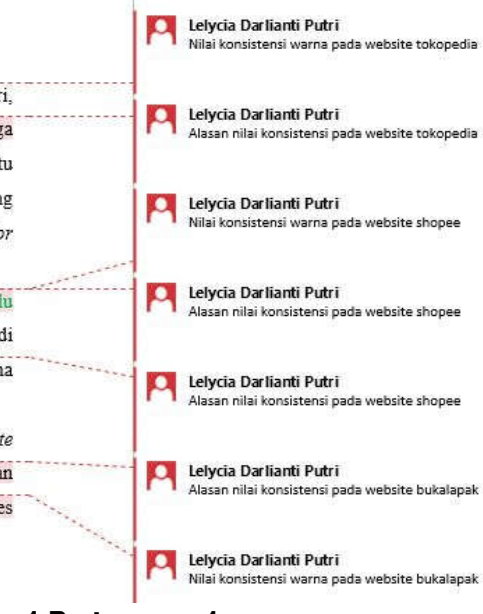

\subsection{Kategorisasi}

Kategorisasi data berfungsi untuk memberi kategori/tema pada hasil reduksi data. Tabel 1 menjelaskan kategorisasi data yang didapat setelah melakukan reduksi data narasumber 1 pertanyaan 1.

Tabel 1. Kategorisasi Data Narasumber 1 Pertanyaan 1

\begin{tabular}{lcccc}
\hline Kode $/$ & Kategori/ & \multicolumn{3}{c}{ Data } \\
\cline { 3 - 5 } Label & Tema & Tokopedia & Shopee & Bukalapak \\
\hline
\end{tabular}




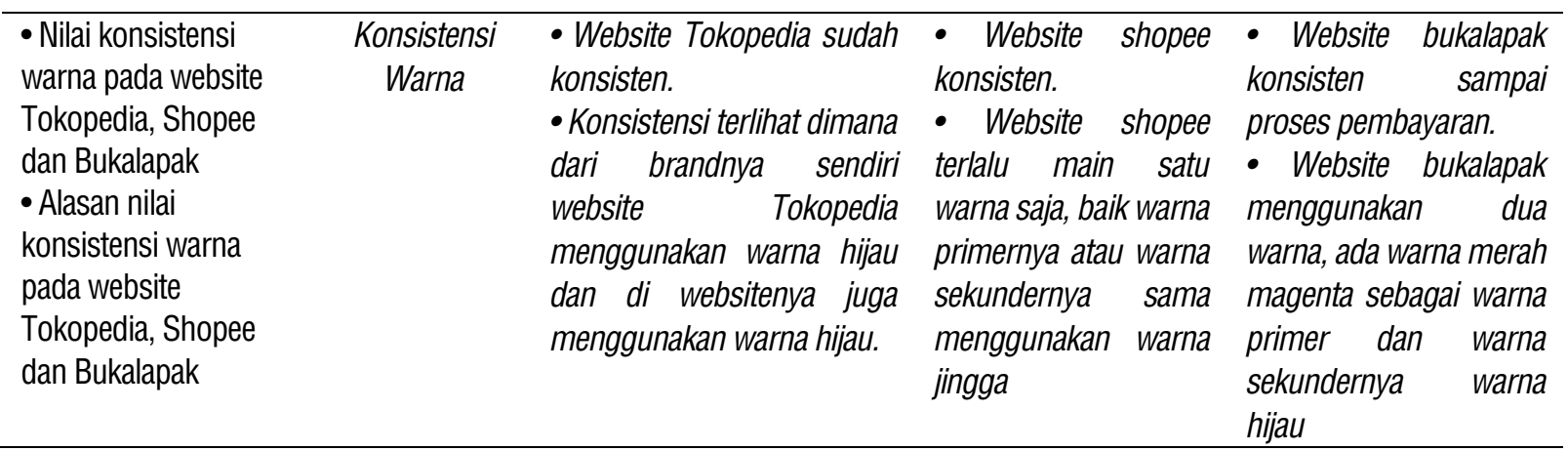

\subsection{Sintesisasi}

Setelah dilakukan reduksi data dan kategorisasi data pada setiap hasil wawancara beberapa narasumber. Kemudian, dilakukan sintesisasi dengan cara merangkum hasil wawancara dari narasumber 1, narasumber 2, dan narasumber 3 yang telah dikategorisasikan pada Tabel 2.

Tabel 2. Sintesisasi

\begin{tabular}{|c|c|c|c|c|}
\hline Kode / & Kategori/ & & Data & \\
\hline Label & Tema & Tokopedia & Shopee & Bukalapak \\
\hline - Nilai konsistensi & Konsistensi & - Website Tokopedia sudah & - Website shopee & - Website bukalapak \\
\hline warna pada website & Warna & konsisten. & konsisten. & konsisten \\
\hline Tokopedia, Shopee & & - Konsistensi terlihat dimana & - Website & proses pembayaran. \\
\hline dan Bukalapak & & brandnya & terlalu main satu & - Website bukalapak \\
\hline - Alasan nilai & & Tokopedia & warna saja, baik warna & menggunakan \\
\hline konsistensi warna & & menggunakan warna hijau & primernya atau warna & warna, ada warna merah \\
\hline pada website & & dan di websitenya juga & sekundernya & magenta sebagai warna \\
\hline Tokopedia, Shopee & & menggunakan warna hijau. & menggunakan warna & primer \\
\hline kalapak & & & jingga & $\begin{array}{l}\text { sekundernya } \\
\text { hijau }\end{array}$ \\
\hline
\end{tabular}

\subsection{Menyusun Hipotesis Kerja}

Dari hasil sintesisasi yang telah diberikan pada Tabel 2, maka didapatkan hipotesis kerja sebagai berikut :

a. User interface pada website Tokopedia memenuhi variabel eight golden rules

b. User interface pada website Shopee tidak memenuhi variabel eight golden rules

c. User interface pada wesbite Bukalapak tidak memenuhi variabel eight golden rules

d. User interface pada wesbite Tokopedia lebih baik dari user interface website Shopee sesuai dengan teori eight golden rules

e. User interface pada website Tokopedia lebih baik dari user interface website Bukalapak sesuai dengan teori eight golden rules

\subsection{Kredibilitas (triangulasi)}

Berikut Tabel 3 adalah kredibilitas atau derajat kepercayaan yang didapat untuk website Tokopedia dari wawancara, observasi dan dokumentasi.

Tabel 3. Kredibiitas Website Tokopedia

\begin{tabular}{|c|c|c|c|}
\hline \multirow[t]{2}{*}{ Kategori /Tema } & \multicolumn{3}{|c|}{ Triangulasi Sumber Data } \\
\hline & Wawancara & Observasi & Dokumentasi \\
\hline $\begin{array}{l}\text { - Konsistensi Warna } \\
\text { - Konsistensi Tata }\end{array}$ & $\begin{array}{l}\text { - Warna dari website } \\
\text { Tokopedia sudah konsisten. }\end{array}$ & $\begin{array}{lr}\text { - Website } & \text { tokopedia } \\
\text { menunjukkan } & \text { begitu }\end{array}$ & $\begin{array}{l}\text { - Html halaman utama yang } \\
\text { menunjukkan warna, tata letak }\end{array}$ \\
\hline Letak & Website Tokopedia & banyak warna hijau dari & dan font/huruf: $\quad<$ body \\
\hline - Konsistensi & menggunakan warna primer & warna tombol, title, icon & style="overflow: initial;"> ... \\
\hline & jjau pada websitenya yang & & \\
\hline
\end{tabular}




\begin{tabular}{|c|c|c|c|}
\hline $\begin{array}{l}\text { - Konsis } \\
\text { Perintah }\end{array}$ & $\begin{array}{l}\text { berasal dari warna brandnya } \\
\text { sendiri. dilihat dari warna } \\
\text { tombol, title, icon, pada } \\
\text { website sudah konsisten } \\
\text { pada seluruh halaman dan } \\
\text { pasti memiliki warna hijau. } \\
\text { Warna hijau tersebut juga } \\
\text { tidak terlalu mencolok } \\
\text { sehingga tidak terlalu ramai. } \\
\text { - Tata letak dari website } \\
\text { Tokopedia sudah konsisten. } \\
\text { Karena desain tata letak dari } \\
\text { website Tokopedia sudah } \\
\text { memenuhi kriteria dari } \\
\text { desain aplikasi jual beli, tata } \\
\text { letak website juga minimalis, } \\
\text { dan memudahkan pengguna } \\
\text { untuk melihat info profil } \\
\text { mereka karena posisi dari } \\
\text { info profil tidak berubah } \\
\text { meskipun berpindah } \\
\text { halaman }\end{array}$ & $\begin{array}{l}\text { yang mewakili warna } \\
\text { brandnya } \\
\text { - Tata letak menunjukkan } \\
\text { urutan yang jelas seperti } \\
\text { pada halaman utama yang } \\
\text { menunjukkan produk- } \\
\text { produk dari website } \\
\text { - Tata letak yang } \\
\text { menunjukkan jarak dan } \\
\text { posisi yang sama }\end{array}$ & 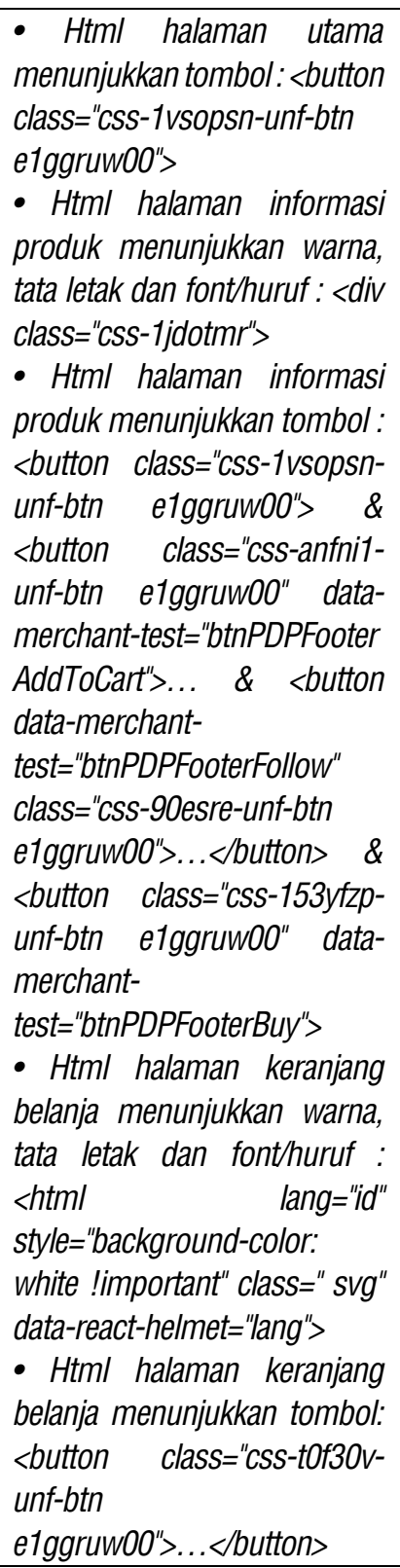 \\
\hline
\end{tabular}

\subsection{Keteralihan (Uraian Rinci)}

Keteralihan merupakan laporan uraian rinci yang dibuat agar pembaca dapat memahami temuan yang diperoleh. Hasil penelitian yang didapat dijelaskan serinci mungkin.

\subsection{Kebergantungan dan Kepastian (Auditing)}

Kebergantungan dan kepastian menggunakan auditing yang dilakukan terhadap proses maupun terhadap hasil atau keluaran. Proses auditing dilakukan oleh dosen pembimbing yang telah mengikuti alur dari penelitian ini dari proses awal hingga akhir. Persetujuan dalam proses ini akan diberikan dengan ditunjukkan lembar proses auditing yang ditanda-tangani oleh dosen pembimbing.

\section{KESIMPULAN}

Dari penelitian yang telah dilakukan pada website Tokopedia, Shopee dan Bukalapak dengan metode kualitatif menggunakan aturan eight golden rules, dapat disimpulkan hasil yang sesuai dengan validitas data pada proses keteralihan yaitu website Tokopedia dapat melebih website Shopee dan website Bukalapak, karena website Tokopedia cenderung memenuhi aturan eight golden rules seperti konsistensi warna, tata letak, fonthuruf yang lebih baik, kegunaan yang universal yang dapat membantu pengguna, interface yang dapat mencegah kesalahan serius, perintah undo/back yang tidak 
membingungkan pengguna, tampilan yang sederhana dan mudah diingat. Selain itu website Shopee dan Bukalapak masih ada bagian yang tidak memenuhi aturan eight golden rules.

\section{UCAPAN TERIMA KASIH}

Puji syukur kepada Allah SWT atas rahmat dan karunia-Nya sehingga penulis dapat menyelesaikan naskah ini. Penulis menyampaikan ucapan terima kasih yang sebesar-besarnya kepada :

a. Ibu Gita Indah Marthasari ST., M.Kom. dan Bapak Wahyu Andhyka Kusuma S.Kom., M.Kom. selaku pembimbing tugas akhir.

b. Ketiga narasumber yang telah bersedia meluangkan waktunya untuk mendukung dan memberikan kontribusi pada penelitian ini.

\section{DAFTAR PUSTAKA}

[1] K. Islam and D. A. Rahayu, "Evaluasi Antarmuka Website Tokopedia menggunakan Metode Heuristic," Electron. J., vol. 8, no. 1, pp. 33-38, 2018.

[2] R. F. A. Aziza and Y. T. Hidayat, "Analisa Usability Desain User Interface Pada Website Tokopedia Menggunakan Metode Heuristics Evaluation," J. Tekno Kompak, vol. 13, no. 1, p. 7, 2019.

[3] P. Krisnayani, K. Resika Arthana, and G. Mahendra Darmawangsa, "Analisa Usability Testing Pada website Menggunakan Metode Heuristic Evaluation," Kumpul. Artik. Mhs. Pendidik. Tek. Inform., vol. 5, no. 1, p. 98, 2016.

[4] iprice insight, "Peta E-Commerce Indonesia," iprice.co.id, 2019. .

[5] M. Yazid, R. A. Pratama, and S. Riyadi, "User Interface Evaluation of Indonesian Online News Portals: Case Study of Vivanews and Detikcom," ICOSI 2014, pp. 455-472, 2017.

[6] M. Solikin, "Evaluasi User Interface pada Aplikasi Pacitan Tourism," pp. 157-166, 2017.

[7] C. B. Susila and M. Suyatno, "Evaluasi User Interface Pada Aplikasi Pacitan Tourism," J. Ekon. dan Tek. Inform., vol. 5, no. 8, pp. 25-37, 2016.

[8] H. Agustiyo, Kusrini, and Henderi, "Evaluasi Usability Aplikasi Pelayanan Masyarakat Jangka Joyoboyo Polres Kediri," Proceeding Semin. Nas. Sist. Inf. dan Teknol. Inf., vol. 1, no. 1, pp. 202-206, 2018.

[9] L. J. Moloeng, Metodologi Penelitian Kualitatif. Bandung: PT. Remaja Rosdakarya, 2014.

[10] Y. S. Guba, E.G and Lincoln, Effective Evaluation. San Fransisco: Jossesey_Bas Publishers, 1981.

[11] B. S. Bachri, "Meyakinkan Validitas Melalui Triangulasi Pada Penelitian Kualitatif," J. Teknol. Pendidik., vol. 10, no. 1, pp. 46-62, 2010.

[12] M. Carcary, "Evaluating Qualitative Research - Implementing the Research Audit Trail," 8th Eur. Conf. Res. Methodol. Bus. Manag. Stud., vol. 7, no. 1, pp. 94-101, 2009. 